(I)

(3)
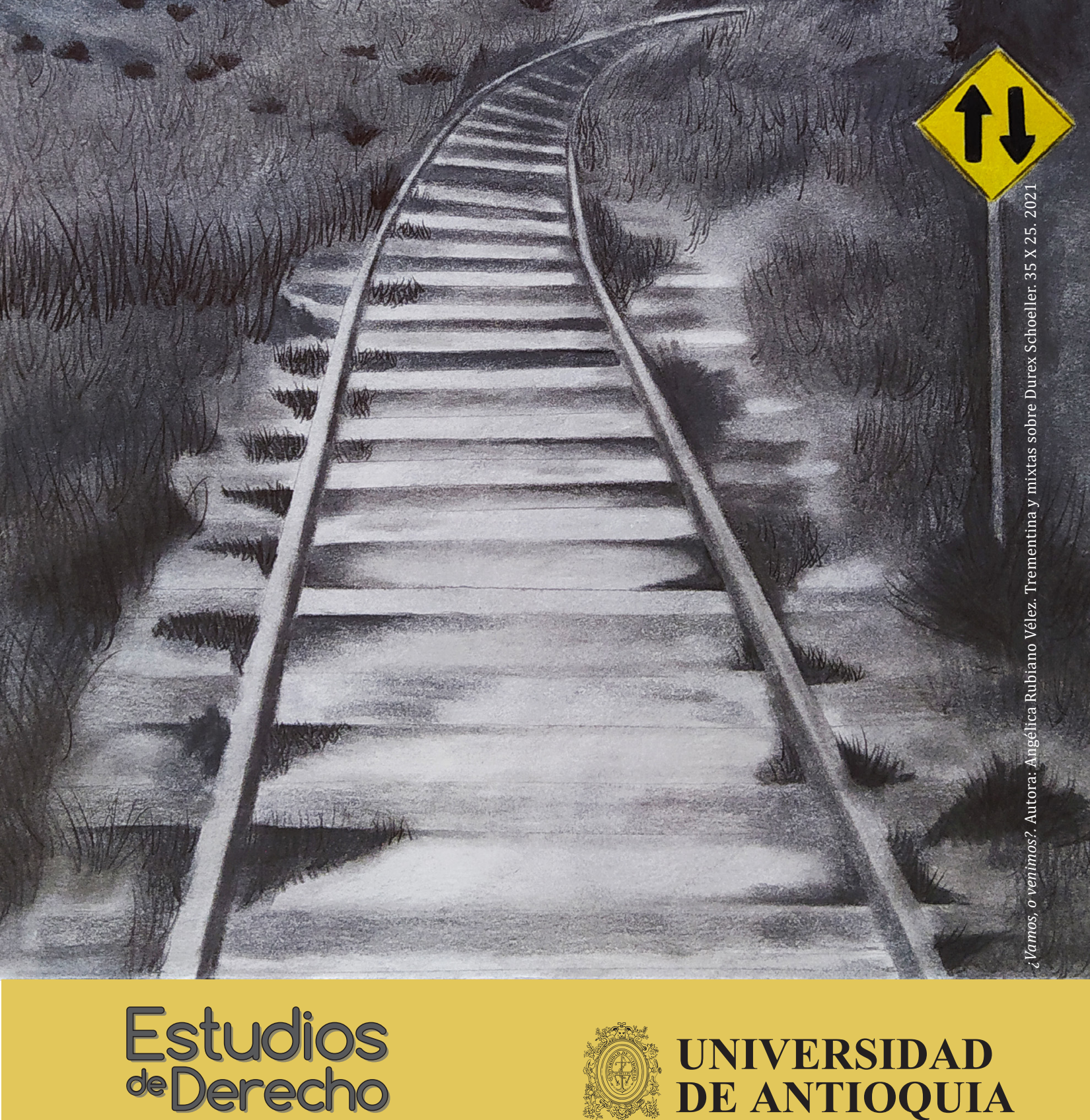


\section{¿Gobierno de los jueces o gobierno del pueblo? Consultas populares ambientales y activismo judicial regresivo en Colombia*}

\section{César Augusto Benavidez Vega**}

\section{Resumen}

En Colombia los conflictos socioambientales han escalado dentro de la expansión judicial en dos frentes (Feoli, 2015), vía judicialización de la política y vía activismo judicial. El primero, cuando los actores en pugna usan mecanismos jurídicos para resolver controversias ambientales (el control previo de constitucionalidad de consultas populares, la acción de tutela contra providencias judiciales, y la nulidad de sentencias de la Corte Constitucional, entre otros), en lugar de debatirlos en escenarios de participación democrática. Mientras que en el segundo la judicatura profiere providencias antiformalistas (López Medina, 2018). A partir de un estudio de caso sobre el régimen de competencias ambientales de las entidades territoriales en consultas populares ambientales, este escrito aborda si: I) ¿la Sentencia SU-095 de 2018 de la Corte Constitucional es activista? Y II) ¿Los cambios jurisprudenciales de esta sentencia obedecen a cambios de magistrados? Se concluye que esta sentencia de unificación sí es activista, y que representa un caso por excelencia del imperio del gobierno de los jueces que se opone al gobierno del pueblo, expresado en las consultas populares realizadas entre 2011-2019, y, por otro lado, que los cambios en la integración de la Corte sí incidieron en el viraje jurisprudencial sobre este tema. Palabras clave: consultas populares ambientales; activismo judicial; Corte Constitucional de Colombia; conflictos socioambientales; judicialización de la política; expansión judicial; antiformalismo.

\section{Government of judges or government of the people? Environmental referendums and judicial activism in colombia}

\section{Abstract}

In Colombia, the socio-environmental conflicts have escalated through the phenomenon of judicial expansion on two fronts (Feoli, 2015), via judicialization of politics and via judicial activism. First of all, when competing actors use different legal mechanisms to resolve environmental issues (such as the prior control of the constitutionality of referendums, the protective action against judicial decisions, and the nullity of rulings of the Constitutional Court), instead of solving them in scenarios of democratic participation, own of other powers. While the second occurs when the judiciary makes decisions that escape the traditional adjudication of the Law, which in terms of López (2018) is typical of anti-formalism. Within the environmental referendums and from the case study of the regime of environmental competences of territorial entities, this text answers two questions: I) Can the ruling SU-095 of 2018 of the Colombian Constitutional Court be classified as activism? And II) Are the changes in the constitutional precedent of the competence of territorial entities to prohibit extractive activities due to changes in the magistrates of the Constitutional Court? This text concludes that, on the one hand, the ruling SU-095 of 2018 is in fact activism and represents a case of excellency of the government of judges that oppose the government of people, expressed in the referendums done and, on the other, that the changes in the composition of the Constitutional Court did influence the change of precedent in this matter. Keywords: Environmental referendums; judicial activism; Colombian Constitutional Court; socio-environmental conflicts; political judicialisation; judicial expansion; anti-formalism.

\section{Governo dos juízes ou governo do povo? Consultas populares ambientais e ativismo judicial na colômbia}

\section{Resumo}

Os conflitos socioambientais na Colômbia têm crescido dentro do fenômeno da expansão judicial em duas vertentes (Feoli, 2015), uma no âmbito da judicialização da política e outra no âmbito do ativismo judicial. No primeiro caso, quando os atores em questão usam diferentes mecanismos jurídicos para resolver temas ambientais (como por exemplo, o controle prévio da constitucionalidade de consultas populares, a ação de tutela contra decisões judiciais e a nulidade de sentenças do Supremo Tribunal Federal), em lugar de resolvê-los nos cenários de participação democrática, próprios de outros poderes. No segundo caso, acontece quando o judiciário emite ordens alheias à adjudicação tradicional do Direito, o que em termos de López (2018) é próprio do antiformalismo. No marco das consultas populares ambientais e partindo de um estudo de caso sobre o regime de competências ambientais das entidades territoriais, este artigo responde a duas perguntas: 1) A sentença SU-095 de 2018 do Supremo Tribunal Federal colombiano pode ser definida como ativista? E 2) As mudanças de precedente constitucional sobre competência de entidades territoriais para proibir atividades extrativistas estão relacionadas as mudanças dos magistrados do Supremo Tribunal Federal? O artigo conclui, por um lado, que a sentença SU-095 de 2018 sim é ativista e que representa um caso típico do governo dos juízes que se opõe ao governo do povo, expressado nas consultas populares realizadas, e por outro lado, que as mudanças na composição do Supremo Tribunal Federal definitivamente incidiram na mudança de precedente neste tema.

Palavras-chave: Consultas populares ambientais; Ativismo judicial; Supremo Tribunal Federal da Colômbia; Conflitos socioambientais; Judicialização da política; Expansão judicial; a Antiformalismo.

* Artículo de investigación. Derivado del curso profundización "Sistema de fuentes: La lucha por la creación del Derecho", impartido en el semestre 2019-2 por el profesor Julián David Agudelo Osorio.

** Abogado de la Universidad de Antioquia, Colombia. Miembro del semillero de Estudios Críticos sobre Democracia de la Facultad de Derecho y Ciencias Políticas de la Universidad de Antioquia, Colombia. Estudiante de especialización en derecho administrativo de la Corporación Universitaria Americana, Colombia. Tesis de pregrado distinguida con mención especial. Ganador del II Concurso de Ensayo Germán Cavelier 2018-2 (Universidad de Antioquia) de la Asociación Cavelier del Derecho. Miembro de la Red Internacional de Investigación sobre Democracia, Derecho y Política desde México y Colombia (Universidad Juárez del Estado de Durango y Universidad de Antioquia). Correo electrónico: cesar.benavidez@udea.edu.co. ORCID: https://orcid.org/0000-0003-4523-9683 


\title{
¿Gobierno de los jueces o gobierno del pueblo? Consultas populares ambientales y activismo judicial regresivo en Colombia
}

\author{
Introducción
}

"No tenemos la última palabra porque seamos infalibles, sino que somos infalibles porque tenemos la última palabra" Jackson.

"Si la política del Gobierno sobre las cuestiones vitales que afectan a todo el pueblo va a ser fijada irrevocablemente por decisiones de la Suprema Corte, en el instante en que así se hace en litigios ordinarios entre partes en acciones personales, el pueblo habrá dejado de ser su propio amo, al renunciar prácticamente a su Gobierno para dejarlo en manos de ese eminente tribunal" Abraham Lincoln.

En sede constitucional, el activismo judicial podría ser abordado desde por lo menos dos perspectivas. La primera en términos críticos, al considerar que los tribunales constitucionales usurpan las funciones de otros poderes públicos o, en general, cuando asumen posturas regresivas. La segunda en términos descriptivos, con relación a las nuevas funciones asumidas por las cortes constitucionales mediante sentencias judiciales en materia de políticas públicas, o con decisiones estructurales, en aras de garantizar la efectividad de los principios y derechos fundamentales de la Constitución Política. Bajo esta perspectiva, la inacción involuntaria o intencionada de algunas autoridades estatales justificaría, de cierta manera, las intervenciones de la judicatura en sus competencias, máxime cuando las omisiones devienen en afectación de derechos subjetivos. A lo largo de este escrito se adoptan ambas perspectivas.

En Colombia, a partir de 1991, gradualmente la Corte Constitucional empezó a emitir sentencias marcadas por una concepción antiformalista del Derecho (nuevo derecho), en reemplazo de la concepción formalista (derecho tradicional), imperante en la Constitución de 1886 (López Medina, 2018). El antiformalismo ha sido clave en el auge del activismo judicial en la jurisdicción constitucional, gracias al cambio de paradigma en la adjudicación del derecho (Guzmán, 2017). 
Los conflictos socioambientales no son ajenos al fenómeno de la expansión judicial de las que habla Feoli (2015). Estas pugnas han migrado de ámbitos de deliberación política (poder legislativo o ejecutivo) hacia estrados judiciales, a través del fenómeno de la judicialización de la política, propio de una visión del nuevo derecho o antiformalismo. Tal como lo evidencian algunas sentencias activistas del Consejo de Estado $^{1}$, la Corte Suprema de Justicia ${ }^{2}$, y los tribunales superiores de distrito judicial ${ }^{3}$, e incluso jueces de categoría circuito.

A tono con el fenómeno de la judicialización, la Corte Constitucional tampoco ha sido la excepción en el ejercicio del control de constitucionalidad abstracto y concreto. Dentro del control concreto se destaca el complejo debate jurisprudencial sobre la competencia constitucional o no de los municipios para prohibir actividades extractivas (hidrocarburos y minería) en sus territorios, mediante el uso de consultas populares. Precisamente, en el marco de judicialización de conflictos socioambientales, la Corte Constitucional profirió una sentencia de unificación jurisprudencial (SU-095 de 2018), en la que revisó los fallos de instancia que decidieron sobre una acción de tutela instaurada por la multinacional Mansarovar Energy Colombia Ltda. Para ellos el Tribunal Administrativo del Meta les había vulnerado sus derechos fundamentales en el trámite del control previo de constitucionalidad de la consulta popular del municipio de Cumaral (Meta) ${ }^{4}$. La Corte le dio la razón al accionante y dejó sin efectos la expresión ciudadana de 7.658 votos, de quienes en su momento acudieron a la consulta popular al amparo del régimen constitucional y legal vigente para la época, así como de los precedentes vinculantes de la Sentencia T-445 de 2016 y el Auto 053 de 2017, ambos de la misma Corte.

El caso Mansarovar Energy Colombia Ltda. contra el Tribunal Administrativo del Meta reabre el debate sobre si existe un gobierno de los jueces o un gobierno del pueblo, en especial cuando los primeros asumen posiciones regresivas respecto

1 Con ocasión de la sentencia de una acción popular, el Consejo de Estado ordenó el diseño y la implementación de medidas de políticas públicas para descontaminar el río Bogotá. Colombia, Consejo de Estado, Sección Primera. (28 de marzo de 2014). Sentencia del 28 de marzo de 2014, expediente número AP-25000-23-27-000-2001-9047901. [CP Marco Antonio Velilla Moreno]. Recuperado de http://www.mincit.gov.co/normatividad/jurisprudencia/ sentencia-ap-25000-23-27-000-2001-90479-01.aspx

2 La Sala de Casación Civil de la Corte Suprema de Justicia declaró a la Amazonía como sujeto de derechos, prohijando el paradigma del nuevo derecho, con una reinterpretación de derechos, mediante sentencia de tutela del 05 de abril de 2018, dentro del proceso radicado STC 4360-2018, [MP Luis Armando Tolosa Villabona]. Recuperado de http:// www.cortesuprema.gov.co/corte/index.php/2018/04/05/corte-suprema-ordena-proteccion-inmediata-de-laamazonia-colombiana/

3 El Tribunal Administrativo de Boyacá declaró al páramo de Pisba como sujeto de derechos, mediante sentencia de tutela del 09 de agosto de 2018, expediente 15238-3333-002-2018-00016-01. [MP Clara Elisa Cifuentes Ortiz]. Recuperado de https://redjusticiaambientalcolombia.files.wordpress.com/2018/08/fallo-pisba.pdf

4 La sentencia reprochada declaró que esta pregunta estaba ajustada a la C.P. de 1991: “¿Está usted de acuerdo ciudadano cumaraleño que dentro de la jurisdicción del Municipio de Cumaral, se ejecuten actividades de exploración sísmica, perforación exploratoria, producción de hidrocarburos?”. 
del alcance de algunos derechos fundamentales de participación ciudadana de los segundos. El propósito de este artículo es analizar la incidencia del activismo judicial en la definición del alcance del ámbito competencial de las autoridades de distintos niveles, en la decisión sobre extracción de recursos naturales no renovables. Para ello se usó la metodología de estudio de caso, en tanto se analizó profundamente la Sentencia SU-095 de 2018 para responder al planteamiento del problema, probar las hipótesis y desarrollarlas (Hernández Sampieri y Mendoza, 2008, como se citarón en Hernández Sampieri, Fernández y Baptista, 2010), aplicando los indicadores de identificación del activismo judicial según Feoli (2015). El análisis involucró el contenido sustancial de la sentencia, los actores que en ella intervinieron, los precedentes horizontales previos aplicables, el contexto normativo en que se expidió, los cambios que introdujo y las consecuencias que ocasionó. Aunado a una perspectiva crítica sobre el particular.

El problema es abordado en dos acápites: en el primero se responde la pregunta I) ¿La Sentencia SU-095 de 2018 es activista? En el segundo si II) ¿Los cambios de precedente constitucional sobre competencia de entidades territoriales para prohibir actividades extractivas obedecen a cambios de magistrados de la Corte Constitucional? El escrito concluye, por un lado, que la Sentencia SU-095 de 2018 sí es activista de acuerdo con Feoli (2015), y representa un caso por excelencia del gobierno de los jueces y, por otro lado, que los cambios en la composición de la Corte Constitucional sí incidieron en el cambio ilegítimo de precedente respecto de las posturas fijadas en la Sentencia T-445 de 2016 y el Auto 053 de 2017, a partir del ejercicio de un activismo judicial regresivo.

\section{I) ¿La Sentencia SU-095 de 2018 es activista?}

Feoli (2015), afirma que el cambio del rol asumido por los jueces constitucionales implica la expansión judicial, conformada por dos fenómenos distintos: la vía judicialización de la política, y la vía activismo judicial (vid. tabla $n . \stackrel{0}{1}$ ). La judicialización de la política consiste en asignarle a los tribunales constitucionales la función de control sobre las otras ramas del poder público, o llevar a los estrados judiciales asuntos que antes se resolvían en el ámbito del poder legislativo o ejecutivo. Dicho de otro modo, la judicialización de la política es la redefinición de las relaciones entre los poderes del Estado 5 .

5 Este fenómeno es similar a lo que Alexy (2009), denomina el carácter antidemocrático de los derechos fundamentales: "la oposición pierde primero en el procedimiento democrático y vence después en el areópago de Karlsruhe". 
¿Gobierno de los jueces o gobierno del pueblo?...

Tabla n. ${ }^{01}$. Fenómenos de la expansión judicial

\begin{tabular}{ccc}
\hline \multirow{2}{*}{ Expansión judicial } & Judicialización de la política & $\begin{array}{c}\text { Redefinición de rela- } \\
\text { ciones entre poderes } \\
\text { públicos }\end{array}$ \\
\cline { 2 - 3 } Activismo judicial & Progresivo \\
\cline { 2 - 3 }
\end{tabular}

Fuente: Elaboración propia a partir de Feoli (2015)

Feoli (2015), agrega que el activismo judicial de los tribunales constitucionales está caracterizado por lo siguiente: i) en la interpretación no se limitan a la literalidad de las normas jurídicas, lo que López Medina (2018), denomina nuevo derecho o antiformalismo, ii) cuentan con la facultad de anular las decisiones de otros poderes del Estado, y iii) podrían ser determinantes en la formulación de políticas públicas (Sieder, Schjolden y Angell, 2011). En todo caso, la nota distintiva del activismo es que la posición del guardián de la Constitución prevalece respecto del criterio de los demás órganos del Estado, en tanto a nivel interno tiene la última palabra en la gestión de conflictos jurídicos ${ }^{6}$ (Feoli, 2015).

Hablar de activismo del tribunal constitucional propiamente dicho, desconocería que en su interior ocurren álgidos debates sobre soluciones razonables para un mismo caso, tanto que algunos magistrados, con sus salvamentos de voto, dan fuertes argumentos oponiéndose a las decisiones mayoritarias. Algunos sectores predican el activismo respecto de las posturas individualmente asumidas por los magistrados del tribunal constitucional. Esta tesis podría ser inconveniente porque a veces los magistrados también cambian de parecer sobre un mismo punto, o por decir lo menos, con el paso del tiempo los van matizando.

Dejando de lado este tipo de análisis, también existen criterios disímiles al momento de catalogar determinada decisión judicial como activista o no, la mayoría de las veces porque se parte de posiciones subjetivas, sin aclarar previamente los parámetros para tener en cuenta. Por ejemplo, para García Jaramillo (2016), el activismo judicial puede ser progresista o regresivo; en el primer caso propende por un alto progreso individual y grupal en el contexto de derechos y principios, mientras que es regresivo cuando procura por recuperar tradiciones sociales y culturales. Según Timm Hidalgo (2017), hay activismo progresista cuando las normas, decisiones y prácticas jurídicas se comprometen con una noción fuerte de igualdad. Mientras que López Sterup (2018), señala que el activismo judicial también puede mantener el statu quo ${ }^{7}$.

6 En igual dirección apuntan Guastini (2010), Guzmán (2017), y Gaviria Díaz (2018).

7 "Si se consideran atentamente los planteamientos sobre qué se entiende como activismo judicial, es claro que existe una tendencia a considerarlos como expresiones de decisiones llamadas "progresistas"; es decir, aquellas que alteran 
En todo caso, las posturas de García Jaramillo (2016), Timm Hidalgo (2017) y López Sterup (2018), puede ser insuficientes para identificar el fenómeno del activismo judicial, al partir de planteamientos muy generales. En contraste, en el contexto latinoamericano los cinco indicadores de Feoli (2015), son parámetros objetivos esclarecedores, tal como se reseña en la tabla n.․ 2, en la definición de cada uno de ellos se alude a su aplicación en el caso colombiano.

Tabla n. ${ }^{\circ} 2$ Indicadores del activismo judicial

\begin{tabular}{l}
\hline \multicolumn{1}{c}{ Indicador } \\
\hline $\begin{array}{l}\text { 1) Contestación de los actos de los } \\
\text { otros poderes (criterio del control) }\end{array}$ \\
\hline \\
2) Reconocimiento o expansión de \\
derechos (criterio interpretativo)
\end{tabular}

Los tribunales constitucionales controlan los actos de los demás poderes del Estado (por ejemplo, a través de anulación de leyes, mediante el control de constitucionalidad abstracto).

Los tribunales constitucionales no se limitan a la literalidad de las disposiciones normativas, sino que pueden reconocer derechos innominados, o expandir (o reducir) el núcleo esencial de los derechos subjetivos expresamente consagrados. La reinterpretación de derechos subjetivos puede ser en más o en menos (Sieder et al., 2011). Lo primero, cuando la creatividad interpretativa se deriva de la aplicación antiformalista del Derecho y sus características (López Medina, 2018). Mientras que lo segundo, se da con la puesta en práctica del derecho tradicional. De esa manera, el activismo judicial es progresista cuando amplía el núcleo esencial de los derechos, mientras que es regresivo cuando los reduce.

3) Uso de sentencias interpretativas

Los tribunales constitucionales modulan los efectos de sus decisiones (temporales, personales, materiales). Deciden la constitucionalidad de normas bajo ciertos entendidos.

Los tribunales constitucionales implementan políticas públicas

4) Definición o redefinición de pocuando en una de sus sentencias ordena a otros poderes del Estalíticas públicas (criterio de diálogo interorgánico)

do desarrollar acciones o programas para satisfacer necesidades sociales en distintos ámbitos. Asunto que de antaño solo era del resorte del poder ejecutivo o legislativo.

\footnotetext{
el status quo, muy seguramente fijado por un grupo dominante en la sociedad. Sin embargo, ¿qué ocurre cuando los jueces, de manera sistemática, se oponen a las transformaciones sociales tramitadas políticamente? El que el juez termine por resolver problemas políticos (como expresión de la judicialización de la política) no significa necesariamente que adopte posturas alejadas del status quo. Es altamente probable que su "activismo" se dirija a mantenerlo, inclusive en contra de las expresiones democráticas. Podría aventurarse que, ante la realidad del funcionamiento de los tribunales constitucionales en el mundo, la genuina actitud activista (por oposición al juez activo que plantea ATIENZA) sea la resistencia (terca) de los jueces y teóricos positivistas-formalistas" (López Sterup, 2018, p. 190).
} 
El juez no se limita a las pretensiones y excepciones de las partes en litigio, yendo más allá de aquello que le ha sido sometido a su consideración (Pásara, 2007).

En el caso colombiano, la regla es que los efectos de las sentencias son inter partes o erga omnes. Los primeros, cuando el control es concreto, los segundos, en ejercicio del control abstracto. Sin

5) Decisión ultra petita embargo, la Corte Constitucional ha postulado como excepciones a la regla el estado de cosas inconstitucional, los efectos inter pares, los efectos inter comunis, y los efectos a simili (Dueñas, 2015). Esto ocurre cuando emite órdenes (insta, exhorta, advierte, etc.) a otras autoridades no accionadas, y, que en principio, no hicieron parte del debate judicial, para que cumplan con determinadas cargas, las cuales por lo general corresponden a políticas públicas, órdenes que suelen constituir sentencias estructurales (Osuna, 2015).

Fuente: Elaboración propia a partir de Feoli (2015)

Para el caso colombiano es conveniente considerar un criterio adicional a los cinco propuestos por Feoli (2015). Se trata del criterio de impacto fiscal, debido a que las decisiones de la Corte Constitucional ejercen impacto económico en las finanzas públicas, incidencia que puede ser notoria o implícita. Esta es evidente cuando la orden implica la creación de una política pública que, muy probablemente, va a requerir de distintos recursos para planearse, ejecutarse y evaluarse. El criterio de impacto fiscal tiene mucho peso, al punto de que se consagrara constitucionalmente la figura del incidente de impacto fiscal (artículo 334 C.P. 1991, Ley 1695 de 2013).

Los cinco indicadores de Feoli (2015), dan mayor claridad al evaluar si determinada sentencia es o no activista. Sin embargo, no se puede negar que también está de por medio la ideología atinente al rol del juez, lo que debería ser su función de aplicar el Derecho, y lo que efectivamente realiza al momento de resolver un problema jurídico ${ }^{8}$. Cada juez adopta posiciones políticas y morales que impregnan sus interpretaciones del Derecho (Gaviria Díaz, 2018; Kennedy, 2010), haciendo que su legitimidad derive de argumentaciones jurídicas razonables.

Entonces, en Colombia ¿Qué significa que una providencia judicial sea activista? Según lo señalado, tales providencias escapan a un ejercicio tradicional de la adjudicación del Derecho para un caso concreto, asumiendo una concepción antiformalista propia del nuevo derecho (López Medina, 2018) conforme las características de la tabla n. $\stackrel{0}{3}$.

8 “La conceptualización, positiva o negativa, del activismo judicial puede reflejar también las posturas en relación a cuál debe ser el límite de la actuación de los jueces cuando toman decisiones que afectan a los otros poderes del Estado. El andamiaje teórico del activismo se nutre de razones no solo descriptivas, sino además de otras que pretenden justificar axiológicamente un tipo de juez ideal" (Feoli, 2015, p. 181). 
Tabla n. ${ }^{\circ}$ 3. Características del derecho tradicional y del nuevo derecho

\begin{tabular}{|c|c|}
\hline Derecho tradicional & Nuevo derecho \\
\hline $\begin{array}{l}\text { "Ahora bien, los jueces de la nación no son, según } \\
\text { sabemos, sino la boca por donde habla la ley, seres } \\
\text { inanimados que no pueden moderar ni su fuerza } \\
\text { ni su rigor" }\end{array}$ & $\begin{array}{l}\text { "Vivimos bajo una Constitución, pero la Constitución } \\
\text { es lo que los jueces dicen que es" } \\
\text { (Justice Hughes) }\end{array}$ \\
\hline \multicolumn{2}{|l|}{ (Montesquieu) } \\
\hline Imperio de la ley & Supremacía de la Constitución \\
\hline Ley & Sentencia judicial \\
\hline Aplicación del Derecho & Creación del Derecho \\
\hline Escuela de la Exégesis & Realismo jurídico norteamericano \\
\hline $\begin{array}{l}\text { Estado de Derecho (supremacía del principio de } \\
\text { legalidad) }\end{array}$ & $\begin{array}{l}\text { Estado Constitucional de Derecho (supremacía de } \\
\text { la Constitución) }\end{array}$ \\
\hline Prevalencia de la seguridad jurídica & Efecto irradiante de los derechos fundamentales \\
\hline Subsunción & Ponderación \\
\hline Reglas & Principios \\
\hline Familia del Civil Law & Familia del Common Law \\
\hline
\end{tabular}

Fuente: Elaboración propia a partir de López Medina (2018)

Además, que una sentencia sea activista no implica necesariamente progresismo, también hay activismo regresivo, como cuando un pronunciamiento pretende cambiar o quizá conservar, falencias estructurales del andamiaje institucional. En el primer evento, con el uso de herramientas creativas que ayudan a concretar en la realidad la ruta de navegación establecida por la Constitución de 1991. En la segunda hipótesis, deshaciendo los avances logrados, a partir de una visión tradicionalista del Derecho.

En lo sucesivo se analizarán los indicadores de Feoli (2015) respecto de la sentencia SU-095 de $2018^{9}$, la cual cumple con los criterios de diálogo interorgánico, interpretativo, fiscal, de control de actos de otros poderes públicos; y al emitir decisiones ultra y extra petita.

La parte resolutiva de la sentencia de unificación refleja el indicador de decisión extra petita y el indicador de definición de políticas públicas (diálogo

9 El problema jurídico de la Sentencia SU-095 de 2018 consistió en determinar si la decisión del Tribunal Administrativo del Meta había incurrido o no en alguna causal específica de procedencia de acción de tutela contra providencias judiciales, con ocasión del trámite de revisión previa de constitucionalidad de la consulta popular del municipio de Cumaral (Meta). Luego de amplias y complejas consideraciones en más de 300 páginas, la Sala Plena del tribunal constitucional concluyó que en ese caso se había presentado: i) defecto sustantivo, ii) violación directa de la Constitución y iii) desconocimiento del precedente constitucional. 
interorgánico), al emitir órdenes al Congreso de la República, a la Agencia Nacional de Hidrocarburos y a otras entidades ${ }^{10}$ que en ningún momento fueron solicitadas por el accionante ni el accionado. En esa dirección, la pregunta de fondo abordada por la Corte es ¿Cuáles son los mecanismos de concertación entre autoridades nacionales y territoriales sobre la gestión de los recursos naturales? Desde la Sentencia C-123 de 2014 se concluyó que existía un vacío normativo. Por ello, el poder ejecutivo emitió el Decreto 2691 de 2014, acatando la orden de exequibilidad condicionada del artículo 37 del Código de Minas. Al año 2018 para el tribunal constitucional el déficit regulatorio no había sido superado, lo que incentivó que exhortara al legislador para regular la materia, teniendo en cuenta trece criterios constitucionales ${ }^{11}$. Sin embargo, con esta decisión afectó el núcleo esencial del derecho de participación ciudadana, en lugar de protegerlo.

A partir del criterio interpretativo, la Corte Constitucional estableció que la participación ciudadana es inoponible al desarrollo económico del país, de modo que las consultas populares territoriales no pueden prohibir actividades extractivistas en los distintos municipios. Esta nueva subregla resulta cuestionable al convertir en meramente nominal la cláusula del Estado social y democrático contemplada en la Constitución. En el caso de Cumaral (Meta), la Corte excluyó la voluntad de los ciudadanos respecto de las decisiones que los afectaban en su territorio. En otras palabras, la Corte hizo una reinterpretación de derechos subjetivos en menos (Sieder et al., 2011), al reducir de forma ilegítima el núcleo esencial del derecho de participación ciudadana en las consultas populares ambientales, privilegiando los principios de Estado unitario, desarrollo económico e interés general, tal como se explica en el segundo acápite de este texto. Es decir, imponiendo el gobierno de los jueces sobre el gobierno del pueblo.

En la Sentencia SU-095 de 2018 también se presenta el criterio de impacto fiscal. La decisión concluyó que el Estado es el propietario del subsuelo y sus recursos naturales no renovables, bajo el entendido de que este está integrado

10 Ordenó al Ministerio de Minas y Energía, Agencia Nacional de Hidrocarburos y Agencia Nacional de Minería, mantener y fortalecer programas, y proyectos para propiciar el diálogo, la comunicación y la información con las entidades territoriales, y sus autoridades locales, con el fin de aplicar los principios de coordinación y concurrencia e información suficiente. Ordenó al Ministerio de Minas y Energía, Ministerio de Ambiente y Desarrollo Sostenible, Autoridad Nacional de Licencias Ambientales Agencia Nacional de Hidrocarburos, Agencia Nacional de Minería, Unidad de Planeación Minero-Energética y Servicio Geológico Colombiano, para que en la política pública del sector minero y de hidrocarburos, robustecieran estrategias de participación ciudadana con entidades públicas. Instó a todos los alcaldes de Colombia para que consideraran los principios de coordinación y concurrencia con las autoridades ambientales, en el ejercicio de sus competencias de ordenamiento territorial.

11 Participación ciudadana y pluralidad; coordinación y concurrencia nación-territorio; inexistencia de un poder de veto de las entidades territoriales para la exploración y explotación del subsuelo y de recursos naturales no renovables; diferencialidad/gradualidad; enfoque territorial; legitimidad y representatividad; información previa, permanente, transparente, clara y suficiente; desarrollo sostenible; diálogo, comunicación y confianza; respeto, protección y garantía de los derechos humanos; buena fe; coordinación y fortalecimiento de la capacidad institucional nacional y territorial; y sostenibilidad fiscal. 
tanto por autoridades nacionales como territoriales. Como titular de esos recursos, y por su explotación percibe una contraprestación económica llamada regalías, que constituyen rentas exógenas de las entidades territoriales (art. 287-4 C.P. de 1991) al corresponder a rentas nacionales, administradas por el Sistema General de Regalías, y que representan un importante ingreso para las finanzas públicas ${ }^{12}$. Este argumento es un reflejo de la preocupación por la incidencia económica de la ejecución de actividades extractivas. Pero ¿será que la preocupación de la Corte por los recursos aportados por el sector minero energético está justificada?

Para algunos actores la explotación de recursos naturales representa una parte importante del PIB colombiano ${ }^{13}$ (Rudas, 2014): del $6 \%$ en 1994, $9 \%$ en 1999, $5,7 \%$ en 2007, y $8 \%$ en $2008^{14}$ (Rudas y Espitia, 2013). Sin embargo, Fierro (2012) y Pardo (2018) afirman lo contrario. De los ingresos percibidos por el Estado a causa de la tributación del sector minero energético existe una brecha considerable entre impuestos potenciales (antes de deducciones, descuentos y exenciones) e impuesto efectivo a la renta. En el caso de hidrocarburos el gasto fiscal de reducciones en el impuesto a la renta está en el $118 \%$ de las regalías percibidas para el periodo 2004 y 2011. Y en la minería "por cada cien pesos recibidos por concepto de regalías, el Estado otorgó a las empresas un descuento en el impuesto a la renta por 132 pesos" (Rudas y Espitia, 2013, p. 154). Los beneficios tributarios otorgados a las empresas extractivas generan disminuciones en el recaudo del impuesto a la renta de minería e hidrocarburos, las cuales exceden ostensiblemente el valor de las regalías de esos sectores (Rudas y Espitia, 2013). Es decir, los incentivos percibidos por el sector minero energético son mayores a los aportes efectivos que este realiza a las finanzas públicas, con lo cual el criterio de impacto fiscal de la Corte pareciera no tener sustento.

De otro lado, en ejercicio del indicador de control de actos de otros poderes públicos, mediante la SU-095 de 2018 la Corte Constitucional dejó sin efectos la sentencia del control previo de constitucionalidad realizado por el Tribunal Administrativo del Meta, y las actuaciones subsiguientes. Esto, pese a que la consulta popular del municipio de Cumaral tuvo lugar el 4 de junio de 2017. En la jornada triunfó la oposición al desarrollo de actividades extractivas de hidrocarburos ${ }^{15}$. De un total de 7.703 sufragantes, 7.658 votaron por el NO, y solo 183 votaron Sí respecto de la pregunta: “ ¿Está usted de acuerdo ciudadano cumaraleño que dentro de la jurisdicción del Municipio de Cumaral, se ejecuten actividades de exploración sísmica, perforación exploratoria, producción de hidrocarburos?”.

\footnotetext{
12 Vid. anexo I de la Sentencia SU-095 de 2018, en especial el acápite titulado "2. Ministerio de Hacienda y Crédito Público".

13 Los recursos percibidos por concepto de regalías difieren de aquellos recaudados por concepto de impuestos, como el de renta o el de valor agregado (Rudas y Espitia, 2013). Además, ver las sentencias C-221 de 1997 y C-1071 de 2003.

14 Para contrastar ver Cárdenas y Reina (2008); Villar, Castro, Forero, Ramírez y Reina (2008).

15 Recuperado de https://www.registraduria.gov.co/Habitantes-de-Cumaral-Meta-dijeron.html
} 
Después de transcurrir más de un año de haberse realizado de la consulta, con la Sentencia SU-095 de 2018, la voluntad de los ciudadanos cumaraleños quedó sin efectos para las autoridades territoriales. Tal decisión contraría los fundamentos normativos de la fuerza vinculante de los resultados de consultas populares ambientales, consagrados en la Ley 134 de 1994 (artículos 8, 55 y 56), y la Ley 1757 de 2015 (artículos 41 y 42). La Corte también desconoció la subregla jurisprudencial sobre la prohibición de invalidar los resultados de una consulta popular (T-1182 de 2001) ${ }^{16}$.

En síntesis, la Sentencia SU-095 de 2018 puede catalogarse como activista. En ella concurren los indicadores de Feoli (2015) de diálogo interorgánico, interpretativo, de impacto fiscal, de control de actos de otros poderes públicos, y el indicador de una decisión ultra y extra petita. No obstante, es regresiva al cambiar de forma ilegítima el precedente judicial horizontal sobre la competencia de los municipios para prohibir actividades extractivistas en sus territorios, fijado en la Sentencia T-445 de 2016 y el Auto 053 de 2017. En el segundo acápite se presentan las razones que lo sustentan. Y después se analiza si este fenómeno tiene relación o no con los cambios de composición de los magistrados de la Corte Constitucional en el año 2017.

\section{II) ¿Los cambios de precedente constitucional sobre la competencia de los municipios para prohibir actividades extractivas obedecen a cambios de magistrados de la corte constitucional?}

Antes de la Sentencia SU-095 de 2018, la Corte Constitucional osciló entre dos posiciones diametralmente opuestas. De un lado, al afirmar que los municipios no tenían competencia para prohibir las actividades extractivas en su ámbito territorial, mientras que la otra postura sostenía lo contrario. La tesis prevaleciente dependía de la conformación de las salas de decisión ${ }^{17}$, aunque a partir de salvamentos y aclaraciones de voto se advertía modificaciones en el balance constitucional (López Medina, 2018).

“Así las cosas, no podría el juez constitucional, alterar la democracia y la participación ciudadana, señalando mediante esta acción de tutela que dicha consulta no debía haberse realizado, pues efectivamente, como se sabe ya se realizó y el pueblo voto a su favor aprobando la medida" (Corte Constitucional, Sentencia T-1182 de 2001).

17 Tal como ocurrió en las Sentencias: T-123 de 2009 (Clara Elena Reales aclaró voto); C-395 de 2012 (aclaraciones de voto de los magistrados Palacio, Pinilla y Sierra); C-123 de 2014 (salvamento de magistrados Calle y Vargas; y aclaraciones de Guerrero, Palacio, López y Rojas); C-619 de 2015 (aclaración de Palacio; salvamento de Rojas y Vargas); C-035 de 2016 (salvamento parcial y aclaración de Calle, Guerrero, Linares, Mendoza, Palacio; aclaración parcial de Ortiz y Vargas; salvamento parcial de Rojas); C-273 de 2016 (salvamento de Guerrero, Linares, Mendozay Pretelt); C-389 de 2016 (aclaraciones de Palacio, Mendoza, Calle, Guerrero; salvamento parcial de Linares; y salvamento parcial y aclaración de Vargas); T-445 de 2016 (aclaración de Rojas); Auto 053 de 2017 (salvamentos de Guerrero, Linares, Lizarazo, y Ortiz); SU-095 de 2018 (aclaración de Ortiz y salvamento de Rojas); C-053 de 2019 (aclaración de Fajardo y Linares). 
Frente a este panorama ¿Cómo explicar posturas contradictorias de la jurisprudencia constitucional? Quizá la respuesta esté en el salvamento de voto conjunto de los magistrados María Victoria Calle Correa y Jorge Iván Palacio Palacio, con ocasión de la Sentencia C-035 de 2016, quienes afirmaron que una de las tantas ficciones jurídicas es la división entre la competencia sobre la gestión del suelo y el subsuelo, como si ambos pudieran ordenarse de forma independiente. Ficción del todo alejada de la realidad, en tanto las decisiones sobre el uno afectan de forma directa o indirecta en el otro. Si en el suelo la apuesta es conservar los recursos naturales excluyendo ciertas actividades extractivas, difícilmente en el subsuelo podría hacerse lo contrario $\sin$ afectar lo primero. 0 si se quiere proteger el subsuelo, pero ejecutar actividades extractivas en el suelo, de todas maneras, se generarían incidencias en el ecosistema, pues este no es divisible. En la Sentencia T-445 de 2016 se concluyó que las actividades extractivas (minería e hidrocarburos) generan distintos impactos tanto en el suelo como en el subsuelo (Vargas, 2014).

Por esta razón, en materia de ordenamiento territorial el Constituyente de 1991 estableció competencias concurrentes entre autoridades nacionales y territoriales, ambas encargadas de planear y ejecutar estrategias, planes, programas y proyectos para gestionar el territorio y sus recursos. La Constitución Política de 1991 en su artículo 80 asignó al Estado la tarea de planeación del manejo y aprovechamiento de los recursos naturales, con el fin de garantizar su desarrollo sostenible. Uno de los fines del ordenamiento territorial es hacer una gestión adecuada de los usos del suelo, mediante su aprovechamiento racional acorde con la función social y ecológica de la propiedad, en aras del desarrollo sostenible (artículo 3-2, Ley 388 de 1997). El artículo 288 superior es la expresión por excelencia del modelo constitucional de competencias compartidas. Además, los numerales 7 y 9 del artículo 313 consagran expresamente la competencia de los concejos municipales para reglamentar usos del suelo, y expedir normas de gestión del patrimonio ecológico.

Desde la perspectiva legal, el texto constitucional ha sido desarrollado mediante la Ley 99 de 1993 (artículo 63), que faculta a las entidades territoriales para ejercer competencias en materia ambiental. La Ley 1454 de 2011 (artículo 26) definió qué se entiende por competencia de la nación o entidades territoriales, y consagró ocho principios del ejercicio de las competencias de las distintas autoridades administrativas (artículo 27). Dentro de estos principios, se destacan los de coordinación, concurrencia y subsidiariedad. Además, el artículo 29 de tal ley distribuyó las distintas competencias entre la nación, los departamentos, los distritos especiales y los municipios

Sin embargo, en otras normas de carácter legal como la Ley 685 de 2001 (Código de Minas) se privilegió la competencia de las autoridades del orden nacional para el otorgamiento de concesiones mineras o de hidrocarburos, en cabeza de la Agencia Nacional de Minería o de la Agencia Nacional de Hidrocarburos, respectivamente. 
Similar cuestión ocurre en la determinación de qué áreas están excluidas o no de dichas actividades, lo que corresponde al Ministerio de Ambiente y Desarrollo Sostenible, y a las corporaciones autónomas regionales (Santaella, 2016). Aún más, el artículo 37 del Código de Minas les prohibía a las autoridades territoriales excluir zonas de minería. La Corte Constitucional fue vacilante respecto del alcance de esta norma, variando su postura cada dos años, dependiendo de la composición de los magistrados de la sala plena. Mediante la sentencia C-395 de 2012 resolvió declararlo exequible al considerar que tal prohibición pertenecía al ámbito de configuración del legislador, quien podía privilegiar el principio de Estado unitario frente al principio de autonomía territorial. Posteriormente, a través de la sentencia C-123 de 2014 lo declaró exequible condicionalmente, bajo el entendido de que las autoridades nacionales debían acordar con sus pares territoriales las medidas pertinentes para la protección del ambiente sano, aplicando los principios de coordinación, concurrencia y subsidiariedad (artículo 288 superior). Y al fin, en la sentencia C-273 de 2016 concluyó su inexequibilidad por violación de reserva de ley orgánica.

No se puede olvidar que la interpretación vacilante de la Corte Constitucional, y las discusiones de distintos sectores institucionales y sociales sobre si los municipios son competentes o no para prohibir actividades extractivas en sus territorios, está enmarcada dentro de los conflictos socioambientales en el país. En ellos intervienen autoridades nacionales y territoriales, así como empresas privadas y comunidades.

Los conflictos sobre el territorio han surgido por falta de acuerdos mínimos entre estos actores. Solo uno de ellos (autoridades nacionales) toma las decisiones y las impone de manera inconsulta a los demás (Santaella, 2016). Al no ser tenidas en cuenta, las comunidades se han movilizado por el ejercicio de sus derechos constitucionales (Pardo, 2013), en especial el de participar en las decisiones que puedan afectar su derecho a un ambiente sano (artículo 79 C.P. 1991). Y es que, en desarrollo de ese mandato constitucional, el artículo 8 de la Ley 134 de 1994 postuló las consultas populares como uno de los mecanismos de participación ciudadana. Aunado a que el artículo 33 de la Ley 136 de $1994^{18}$ estableció la obligación de realizar consulta popular cuando el desarrollo de un proyecto minero amenazara con el cambio significativo del uso del suelo.

Según Santaella (2016), en Colombia la alta ocurrencia de conflictos socioambientales ${ }^{19}$ incentivó la realización de distintas consultas populares, como manifestación de la movilización ciudadana para prohibir actividades extractivas y en contra de las decisiones unilaterales de autoridades nacionales. Algunas de las consultas emblemáticas fueron las de Tauramena (Casanare), Monterrey (Casa-

18 Esta norma fue declarada inexequible mediante la Sentencia C-053 de 2019.
19 Vid. Atlas de Justicia Ambiental. Recuperado de https://ejatlas.org/country/colombia 
nare), Piedras (Tolima), Pijao (Quindío), Arbeláez (Quindío), Cajamarca (Tolima), Gachativá (Boyacá), Cumaral (Meta), Cabrera (Cundinamarca), entre otras.

Frente al auge de la participación ciudadana, los defensores del sector minero energético también emplearon herramientas jurídicas para oponerse a sus contendores, tales como demandas de revisión en contra de los acuerdos municipales que implementaron resultados de las consultas populares realizadas, infundir temor a concejales y alcaldes sobre eventuales investigaciones penales y disciplinarias (Negrete, 2017), y acciones de tutela en contra de las sentencias de los tribunales administrativos que resolvieron el control previo de constitucionalidad de las preguntas, porque las habían declarado constitucionale ${ }^{20}$. En otras palabras, los actores de conflictos socioambientales judicializaron sus disputas (Feoli, 2015), llevándolas al foro de la judicatura.

Entre los años 2011 y 2019 se promovieron en Colombia 28 consultas populares ambientales, en promedio 3.5 anuales. Sin embargo, de estas solo 12 llevaron a los ciudadanos a las urnas. Las demás no pudieron realizarse porque, o bien no superaron el control previo de constitucionalidad, o si lo superaron los actores del sector minero energético las suspendieron mediante acciones de tutela ${ }^{21}$, o si lo uno u otro no ocurría, entonces la talanquera era la falta de recursos económicos para financiar los gastos del sufragio.

En 8 consultas promovidas la pregunta fue declarada inconstitucional ${ }^{22}$, entre otras razones por ser manifiestamente sugestiva, o porque a juicio de los tribunales administrativos los concejos municipales carecían de competencia para convocarlas. Mientras que otras 8 consultas no se realizaron porque el Ministerio de Hacienda y Crédito Público no autorizó las partidas presupuestarias respectivas a la Registraduría Nacional del Estado Civil (Negrete, 2017). Esto ocurrió en cuatro municipios del Meta (La Macarena ${ }^{23}$, Granada ${ }^{24}$ Castillo ${ }^{25}$ y Cubarral), uno

El texto de la pregunta sometida a votación en la consulta debe ser de carácter general, y estar redactado de forma clara, para responderse con un sí o un no (artículo 8 y 52, Ley 134 de 1994; literal b) artículo 38, Ley 1757 de 2015). Los tribunales administrativos son las autoridades judiciales encargadas de verificar el cumplimiento de la exigencia legal de claridad, objetividady lealtad (inciso segundo artículo 53, Ley 134 de 1994, y artículo 21, Ley 1757 de 2015). Esta medida pretende velar por la libertad del votante al momento de ejercer su derecho de participación ciudadana, cuestionando preguntas sugestivas, confusas, engañosas, capciosas, etc. (Sentencias: C-551 de 2003, C-592 de 2012, C-150 de 2015, T-445 de 2016).

21 Situación acaecida con las consultas populares de Monterrey (Casanare), y San Bernardo (Cundinamarca).

22 Los tribunales administrativos declararon inconstitucionales los textos de las preguntas de las consultas populares de Onzaga (Santander), Recetor (Casanare), Pijao (Quindío), Pueblorrico (Antioquia), Gachantivá (Boyacá), Ibagué (Tolima), Cajamarca I (Tolima) y Cogua I (Cundinamarca).

23 Vid. https://www.eltiempo.com/colombia/otras-ciudades/no-se-realizo-la-consulta-minera-en-la-macarena-meta-155638

24 Vid. https://sostenibilidad.semana.com/medio-ambiente/articulo/consulta-popular-en-granada-se-suspende-por-falta-deplata/38797

25 Vid. https://www.rcnradio.com/colombia/llanos/tres-municipios-del-meta-con-consultas-populares-mineras-suspendidas 
de Casanare (Monterrey), uno de Santander (Peñón), uno de Cundinamarca (Une), y uno de Quindío (Córdoba) ${ }^{26}$.

Los múltiples pronunciamientos del Consejo de Estado en sede de acciones de tutela a favor y en contra de consultas populares ambientales también reflejan la judicialización de estos temas. Además, ha existido un choque de trenes entre el tribunal constitucional y el órgano de cierre de lo contencioso administrativo sobre el régimen de competencias de los municipios en materia ambiental ${ }^{27}$. Solo hasta la Sentencia SU-095 de 2018 se unificó jurisprudencia sobre el particular, pero imponiendo el gobierno de los jueces mediante un activismo judicial regresivo, por encima del gobierno del pueblo, quien se estaba pronunciando a través de las consultas populares ambientales.

La Sentencia SU-095 de 2018 permite visualizar la concurrencia de distintas autoridades jurisdiccionales sobre un mismo tópico, aunque a la luz de perspectivas diferentes, tal como se indicó supra respecto del control de constitucionalidad del artículo 37 del Código de Minas (Ley 685 de 2001). En particular, el Tribunal Administrativo del Meta como juez natural del control previo de constitucionalidad de la convocatoria de consulta popular en Cumaral (Meta). El Consejo de Estado (Sección Cuarta y Quinta) como juez de tutela en sede de primera y segunda instancia. Y la Corte Constitucional como órgano de cierre de la jurisdicción constitucional, con ocasión de la revisión de los fallos de tutela de instancia, ejerciendo el indicador de control de otros poderes del que habla la tabla $n .{ }^{\circ}$ 2. No obstante, que el tribunal constitucional emita la última palabra sobre un problema jurídico no implica que esté exento de vulnerar derechos fundamentales, en especial al cambiar su jurisprudencia de forma ilegítima, al asumir un activismo regresivo ${ }^{28,29}$.

26 Vid. anexo I de la sentencia SU-095 de 2018, en especial respuesta de la Registraduría al auto de pruebas, acápite titulado "3. Registraduría Nacional del Estado Civil”.

27 Al respecto, se deben destacar las siguientes providencias del Consejo de Estado: En la Sentencia del 05 abril 2018 , radicado 11001-03-15-000-2017-02389-01 [CP Jorge Octavio Ramírez], se concluyó que el mecanismo de coordinación por excelencia entre autoridades municipales y nacionales es el plan de ordenamiento territorial o su equivalente; la Sentencia del 04 de octubre de 2018, radicado 11001-03-15-000-2018-00083-01 [CP Jorge Octavio Ramírez], ratificó que a los municipios les estaba permitido prohibir minería, recogiendo los precedentes constitucionales y de lo contencioso sobre el particular: T-123 de 2009, C-983 de 2010, C-339 de 2012, C-395 de 2012, C-123 de 2014, C-619 de 2015, C-035 de 2016, C-273 de 2016, C-298 de 2016, C-389 de 2016, T-445 de 2016 y Auto 053 de 2017. En todas ellas el asunto de fondo era la ponderación entre los principios de Estado unitario y autonomía territorial (Estado nivel central versus Estado local).

28 "De esta manera, el legislador es quien desarrolla los derechos fundamentales dentro del margen de libertad que la Constitución le traza, y el Tribunal Constitucional es quien controla las regulaciones legislativas, y quien tiene la última palabra acerca de su constitucionalidad. Sin embargo, esto no quiere decir que la última palabra proferida por el Tribunal Constitucional exprese la verdad, o en otros términos la respuesta correcta a cada problema de constitucionalidad. La decisión del Tribunal representa sólo una lectura del texto de la Constitución, efectuada a la luz de las circunstancias del caso concreto, con limitaciones de tiempo y de conocimientos, por unos jueces inmersos en la sociedad y poseedores por ende de una visión política de la misma” (Bernal, 2005, p. 45).

29 Vid. Saffon y García Villegas (2011): “No debe confundirse activismo con progresismo, pues el activismo no necesariamente es progresista. Ver Uprimny (2006: 127). El mejor ejemplo de activismo conservador puede verse en 
Se habla de activismo judicial regresivo porque hubo cambio ilegítimo de postura respecto de los precedentes horizontales vinculantes fijados en la Sentencia T-445 de 2016 y el Auto 053 de 2017, al no cumplir con la carga de la argumentación y carga de la transparencia, en detrimento de la cosa juzgada constitucional, la seguridad jurídica, la buena fe, la igualdad y la confianza legitima. Esto no significa que la Corte no pueda cambiar su jurisprudencia, lo cuestionable es que lo haga después de que ella misma lo confirma mediante auto que resuelve solicitud de anulación de su sentencia.

En la Sentencia T-445 de 2016 se revisó una acción de tutela en contra de la sentencia del Tribunal Administrativo del Quindío que declaró inconstitucional la pregunta de la consulta popular de Pijao (Quindío). En este caso la Corte expresamente fijó como uno de sus problemas jurídicos: “¿Establecer si los entes municipales, por intermedio de una consulta popular y haciendo uso de su competencia para regular el uso del suelo y garantizar un ambiente sano, pueden prohibir o excluir de la totalidad de su territorio la actividad minera?" Asunto que resolvió en el numeral segundo de la parte resolutiva, precisando que las entidades territoriales sí cuentan con esta competencia constitucional, "incluso si al ejercer dicha prerrogativa terminan prohibiendo la actividad minera".

Ante una decisión que daba tal prevalencia al derecho de participación ciudadana y a la autonomía de las entidades territoriales, los actores del sector minero energético $^{30}$ no dudaron en actuar judicializando ese conflicto socioambiental, solicitando la anulación de la Sentencia T-445 de 2016, argumentando la violación de algunos precedentes ${ }^{31}$. Esto originó el Auto 053 de 2017, en el que la Corte concluyó que la Sentencia T-445 de 2016 no generaba cambio jurisprudencial alguno, antes bien era una reiteración de la jurisprudencia constitucional vigente en ese momento. Por tanto, la sala plena de la Corte negó la solicitud de nulidad y mantuvo en firme las subreglas de la Sentencia T-445 de 2016. Pero allí también hubo fuertes discrepancias entre los magistrados. La ponencia del magistrado Jorge Iván Palacio Palacio solo contó con 5 votos a favor y 4 opiniones disidentes. La tabla n. 4 extracta el problema jurídico, consideraciones relevantes y parte resolutiva de la Sentencia T-445 de 2016, el Auto 053 de 2017 y la SU-095 de 2018.

la actuación de la Suprema Corte de Justicia de los Estados Unidos a comienzos del siglo XX. Además, como anota Santos, 'hasta hace muy poco [,] los ejemplos más conocidos de activismo judicial eran políticamente conservadores, por no decir reaccionarios' (Santos, 2001: 85)" (p. 77).

30 Agencia Nacional de Minería, Agencia Nacional de Defensa Jurídica del Estado, Ministerio de Minas y Energía, Asogravas, Unidad de Planeación Minero Energética (UPME), Cremades y Calvo-Sotelo Abogados, Asociación de Mineros e Hidrocarburos del Tolima, Asociación Colombiana de Minería, y Procuraduría General de la Nación.

31 Para ellos precedentes sentados en las Sentencias: C-517 de 1992, C-520 de 1994, C-149 de 2010, C-983 de 2010 , C-395 de 2012, C-123 de 2014, C-150 de 2015, C-035 de 2016, C-273 de 2016 y C- 298 de 2016. 
¿Gobierno de los jueces o gobierno del pueblo?...

Tabla n. ${ }^{0} 4$. Precedentes constitucionales sobre consultas populares en materia de explotación de actividades extractivas

\begin{tabular}{l} 
T-445 de 2016 \\
\hline Problema jurídico \\
Determinar si el Tribunal Admi- \\
nistrativo del Quindío vulneró \\
los derechos fundamentales al \\
debido proceso, al acceso a la \\
administración de justicia y a la \\
participación ciudadana de la \\
accionante, al declarar incons- \\
titucional la pregunta puesta \\
a consideración por el alcalde \\
de Pijao: \\
¿Establecer si los en tes \\
municipales, por intermedio \\
de una consulta popular y \\
haciendo uso de su competencia \\
para regular el uso del suelo y \\
garantizar un ambiente sano, \\
pueden prohibir o excluir de \\
la totalidad de su territorio la \\
actividad minera?
\end{tabular}

\section{Parte motiva}

“El Tribunal desconoció así evidentemente el contenido de esa providencia (C-123 de 2014) y el precedente constitucional que creó según el cual aún en el marco de la realización de actividades mineras en el territorio nacional debe garantizarse un grado de participación y que esta además debe ser activa y eficaz, lo cual puede llevar incluso a la manifestación de voluntad por parte del ente territorial de oponerse a la actividad minera".

\section{Parte motiva}

"La sentencia T-445 de 2016 no genera un cambio jurisprudencial ya que su contenido configura una reiteración de la jurisprudencia constitucional referente a las competencias de las entidades territoriales para regular los usos del suelo y ordenar su territorio.

Dado que no se configuran la causal de cambio de jurisprudencia ni la de incongruencia entre la parte motiva y la parte resolutiva de la sentencia, no se entiende violado el debido proceso que daría lugar a la eventual nulidad de la sentencia.

Por tanto, lo que ha hecho la Sala de Revisión en uso de su facultad jurisdiccional es aplicar la Constitución, la jurisprudencia constitucional y la ley a un caso concreto y nuevo (sentencia fundadora)". (Énfasis propio)
SU-095 de 2018

\section{Problema jurídico}

Determinar si la sentencia del Tribunal Administrativo del Meta, incurrió o no en alguna causal específica de procedencia de acción de tutela contra providencias judiciales, con ocasión del trámite de revisión previa de constitucionalidad de la consulta popular del municipio de Cumaral (Meta), sobre si en ese territorio se deben desarrollar o no actividades de exploración y explotación de hidrocarburos.

\section{Parte motiva}

"En el contexto, la Sala Plena de esta Corporación debe aclarar que se apartará de las consideraciones y de la decisión adoptada por la Sala Sexta de Revisión de la Corte Constitucional que profirió la sentencia T-445 de 2016, y que en el numeral segundo de la parte resolutiva de la sentencia precisó 'que los entes territoriales poseen la competencia para regular el uso del suelo y garantizar la protección del medio ambiente, incluso si al ejercer dicha prerrogativa terminan prohibiendo la actividad minera". Lo anterior, teniendo en cuenta que en dicha providencia la Sala Sexta hizo una interpretación limitada y aislada de postulados y principios definidos en la Constitución Política, que la llevaron a autorizar a las autoridades locales para prohibir la minería'. 


\begin{tabular}{lll}
\hline Parte resolutiva & Parte resolutiva & Parte resolutiva \\
"SEGUNDO.- PRECISAR que & “Tercero: NEGAR la solicitud de & "OCTAVO. -INSTAR a los alcaldes \\
los entes territoriales poseen & la nulidad de la sentencia T-445 & de los municipios del país para \\
la competencia para regular & de 2016, proferida por la Sala & que en el marco de sus competen- \\
el uso del suelo y garantizar la & Sexta de Revisión de la Corte & cias de ordenamiento territorial \\
protección del medio ambiente, & Constitucional, instaurada por la & tengan en cuenta los principios de \\
incluso si al ejercer dicha pre- & Agencia Nacional de Minería, el & coordinación y concurrencia con \\
rrogativa terminan prohibiendo & Ministerio de Minas ynergía-con & las autoridades nacionales". \\
la actividad minera". & Coadyuvancias de Asogravas, la & \\
& Asociación Colombiana de Minería \\
& y la Procuraduría General de la \\
& Nación-Grupo Asesores en Minas, \\
& Hidrocarburos y Regalías". & \\
&
\end{tabular}

Fuente: Elaboración propia

Si las Sentencias T-445 de 2018, Auto 053 de 2017, y SU-095 de 2018 fueron emitidas por la Corte Constitucional, entonces ¿Cómo explicar que ella misma al cabo de poco más de un año adopte soluciones radicalmente opuestas frente a problemas jurídicos semejantes? La respuesta podría estar en la alteración del balance constitucional del que habla López Medina (2018), y que está condensado en la tabla n.․ 5 , a partir de qué magistrados conformaron cada sala de decisión.

Según López Medina (2018), el balance constitucional, también conocido como sombra decisional, es el lugar donde se sitúa la doctrina mayoritaria de la Corte entre dos puntos opuestos. Y es que la sombra decisional se produce porque la Corte está integrada por diez salas, una plena con nueve magistrados ${ }^{32}$, y nueve salas de revisión de acciones de tutela de tres magistrados ${ }^{33}$ cada una.

32 Artículo 44 de la Ley 270 de 1996.

33 Artículo 34 del Decreto 2591 de 1991. 
¿Gobierno de los jueces o gobierno del pueblo?...

Tabla n. ${ }^{0} 5$. Composición de las salas de decisión de la Corte Constitucional (T-445 de 2016, Auto 053 de 2017 y SU-095 de 2018)

\begin{tabular}{|c|c|c|}
\hline T-445 de 2016 & Auto 053 de 2017 & SU-095 de 2018 \\
\hline 1) Jorge Iván Palacio Palacio & 1) Jorge Iván Palacio Palacio & 1) José Fernando Reyes Cuartas ${ }^{34}$ \\
\hline 2) Jorge Ignacio Pretelt Chaljub & 2) Aquiles Arrieta Gómez & 2) Cristina Pardo Schlesinger ${ }^{35}$ \\
\hline \multirow[t]{7}{*}{$\begin{array}{l}\text { 3) Alberto Rojas Ríos } \\
\text { (Con aclaración de voto) }\end{array}$} & 3) Alberto Rojas Ríos & $\begin{array}{l}\text { 3) Alberto Rojas Ríos } \\
\text { (Con salvamento de voto) }\end{array}$ \\
\hline & $\begin{array}{l}\text { 4) Antonio José Lizarazo Ocampo } \\
\text { (Con salvamento de voto) }\end{array}$ & 4) Antonio José Lizarazo Ocampo \\
\hline & $\begin{array}{l}\text { 5) Gloria Stella Ortiz Delgado } \\
\text { (Con salvamento de voto) }\end{array}$ & $\begin{array}{l}\text { 5) Gloria Stella Ortiz Delgado } \\
\text { (Con aclaración de voto) }\end{array}$ \\
\hline & $\begin{array}{l}\text { 6) Luis Guillermo Guerrero Pérez } \\
\text { (Con salvamento de voto) }\end{array}$ & 6) Luis Guillermo Guerrero Pérez \\
\hline & 7) María Victoria Calle Correa & $\begin{array}{l}\text { 7) Carlos Bernal Pulido }{ }^{36} \\
\text { (Ausente en comisión) }\end{array}$ \\
\hline & 8) Luis Ernesto Vargas Silva & $\begin{array}{l}\text { 8) Diana Fajardo Rivera }{ }^{37} \\
\text { (Impedimento aceptado) }\end{array}$ \\
\hline & $\begin{array}{l}\text { 9) Alejandro Linares Cantillo } \\
\text { (Con salvamento de voto) }\end{array}$ & $\begin{array}{l}\text { 9) Alejandro Linares Cantillo } \\
\text { (Impedimento aceptado) }\end{array}$ \\
\hline Votación & Votación & Votación \\
\hline 3-0 & $5-4$ & $5-1^{38}$ \\
\hline
\end{tabular}

Fuente: Elaboración propia

34 José Fernando Reyes Cuartas fue elegido magistrado de la Corte Constitucional para el periodo marzo 2017-marzo 2025, ternado por la Corte Suprema de Justicia. Antes de ingresar a la Corte era magistrado del Tribunal Superior del Distrito Judicial de Manizales.

35 Cristina Pardo fungió como secretaria jurídica durante la presidencia de Juan Manuel Santos, desde el 2010 hasta 2017. Fue elegida magistrada de la Corte Constitucional el 16 de mayo de 2017, e hizo parte de la terna de Santos para el periodo abril de 2017- abril de 2025. Sus antecesores fueron Aquiles Arrieta Gómez (magistrado encargado), y Jorge Pretelt Chaljub, entre otros. Pardo fue la magistrada ponente de la Sentencia SU-095 de 2018. Desde antes de ser elegida magistrada de la Corte, algunos sectores de opinión pública la catalogaban como conservadora en cuanto a sus posturas jurídicas, y advertían que con su designación la Corte Constitucional iba a dar un viraje. Vid. https:// lasillavacia.com/historia/las-ternas-de-santos-pueden-llevar-una-corte-menos-activista-60475

36 Carlos Bernal Pulido fue elegido magistrado de la Corte Constitucional para el periodo mayo 2017-mayo 2025, ternado por el presidente Juan Manuel Santos. Antes de ingresar a la Corte fungió como investigador asociado de la Macquarie University (Sídney, Australia), destacado jurista en la academia.

37 Diana Fajardo Rivera fue elegida magistrada de la Corte Constitucional para el periodo junio 2017-junio 2025, ternada por la Corte Suprema de Justicia, para suceder al magistrado Luis Ernesto Vargas Silva. Antes de ingresar a la Corte se desempeñó como directora de Políticas y Estrategias para la Defensa Jurídica de la Agencia Nacional de Defensa Jurídica del Estado, desde el 03 de julio de 2013 hasta el 2017. Esta entidad pública fue una de las que solicitó la nulidad de la Sentencia T-445 de 2016.

38 La Sentencia SU-095 de 2018 solo fue decidida por 6 magistrados, porque 2 de ellos se declararon impedidos (Alejandro Linares Cantilloy Diana Fajardo Rivera) y uno estaba ausente en comisión (Carlos Bernal Pulido). La decisión quedó 5 contra 1, porque el magistrado Alberto Rojas Ríos salvó su voto, mientras que Gloria Stella Ortiz Delgado presentó aclaración. 
La tabla n. 5 muestra que la minoría, es decir, los 4 magistrados que salvaron el voto en el Auto 053 de 2017, se convirtieron en mayoría en el año 2018. Esto gracias a la alteración del balance constitucional, producto del ingreso de 4 nuevos magistrados (José Fernando Reyes Cuartas, Cristina Pardo Schlesinger, Carlos Bernal Pulido y Diana Fajardo Rivera). En contraste, la tesis del magistrado Alberto Rojas, que había sido la mayoritaria en 2017, fue el único voto disidente en 2018, a raíz de la salida de sus copartidarios Jorge Iván Palacio Palacio, Aquiles Arrieta Gómez, María Victoria Calle Correa y Luis Ernesto Vargas Silva, y la postura contraria de los "nuevos" integrantes.

El magistrado Alejandro Linares Cantillo ${ }^{39}$ anticipó las implicaciones de la "nueva Corte", cuando al participar como ponente en el Congreso Nacional de Minería de 2017 (Cartagena de Indias) afirmó:

¿Qué es lo que está pasando al interior de la Corte, será que la mayoría de los magistrados de la Corte Constitucional, la mayoría, se enloquecieron? ¿Será que es un tema ideológico lo que está ocurriendo? ¿Yo como minoritario en esa Corte digo porque será que hay más de cinco magistrados que piensan distinto a mí?, y para explicar el tema tengo una tesis, espero que esa tesis no me genere recusaciones en el futuro, y es que ante la inactividad del Estado, llámese Estado el estado local, el legislativo o será que el ejecutivo se durmió, ¿qué es lo que está pasando?, y yo diría mi explicación es que la mayoría de la Corte Constitucional decidió, ante la inactividad de los otros órganos del Estado, decidió la misma Corte empezar a decir que tenemos que ser activos para imponer lo que se llama la licencia social para poder operar, esa es mi explicación a lo que ha venido pasando, se puede criticar el activismo judicial pero yo y siendo miembro de un cuerpo colegiado, tengo que defender ese cuerpo colegiados a pesar que en el $\mathbf{1 0 0} \%$ de las veces en las decisiones sobre minería no he estado de acuerdo con las posiciones mayoritarias de la Corte.

[...] Lo otro, el tema de la seguridad jurídica, yo llamaría la atención en que el entorno cambió y lo que hace la Corte, no es que se haya enloquecido, sino lo que en cierta forma refleja esos cambios en el entorno en las decisiones judiciales, algunas de ellas obviamente excesivas, fallos extrapetitas sobre todo en materia de tutela, pero yo creo que con la nueva Corte este va a ser un tema que va a volver a un cauce natural en la medida en que la mayoría de los nuevos elegidos son copartidarios del doctor Luis Emilio

39 Alejandro Linares Cantillo fue elegido magistrado de la Corte Constitucional para el periodo octubre 2015-octubre 2023, ternado por el presidente Juan Manuel Santos. Antes de ingresar a la Corte trabajó como vicepresidente jurídico de Ecopetrol S.A. de 2014 a 2015. Esto explica su interés por el sector minero energético. 
¿Gobierno de los jueces o gobierno del pueblo?...

\section{Sierra, es gente, digamos, más sensata y menos progresista, diría}

yo (Asociación Colombiana de Minería, 2017) ${ }^{40}$. (Énfasis propio).

"Los nuevos elegidos", en palabras de Linares, corresponden a los cambios del año 2017 en casi la mayoría de los magistrados de la Corte Constitucional. 4 de los 9 jueces finalizaron sus periodos constitucionales de ocho años. Los magistrados 1) Jorge Iván Palacio Palacio, 2) Aquiles Arrieta Gómez, 3) María Victoria Calle Correa y 4) Luis Ernesto Vargas Silva fueron sucedidos por 1) José Fernando Reyes Cuartas, 2) Cristina Pardo Schlesinger, 3) Carlos Bernal Pulido, y 4) Diana Fajardo Rivera, respectivamente. Esto significa que, desde el Congreso de 2017 de la Asociación Colombiana de Minería, el magistrado Alejandro Linares advirtió la llegada a la Corte de magistrados que podrían tener una postura más cercana a la suya, lo que desencadenó en decisiones regresivas, como la ocurrida en la Sentencia SU-095 de 2018. En efecto, los magistrados Reyes, Bernal, Pardo y Fajardo que ingresaron entre tales años tenían posturas "menos progresistas", y con posibles conflictos de intereses. La posesión de Fajardo (exservidora de la Agencia Nacional de Defensa Jurídica del Estado), Linares (quien trabajó para Ecopetrol S.A.) y Pardo (exsecretaria jurídica de la Presidencia de la República) no guarda armonía con el principio de independencia e imparcialidad de los jueces. Ellos mutaron de ser parte contendiente a favor del sector minero energético a jueces y resolver los conflictos jurídicos socioambientales. Disonancia referida al elemento subjetivo del que habla Aguiló Regla (2003), en especial sobre las inclinaciones políticas de los jueces ${ }^{41}$.

En definitiva, en la Sentencia SU-095 de 2018 se unificó jurisprudencia sobre la no competencia de las autoridades territoriales para prohibir actividades extractivas en sus territorios. La intervención de dos de los nuevos magistrados (Pardo y Reyes) fue determinante en el cambio jurisprudencial ilegítimo y regresivo realizado por la sala plena de la Corte Constitucional, respecto de la Sentencia T-445 de 2016 y el Auto 053 de $2017^{42}$. ¿Por qué? Al permitir reconfigurar las mayorías

40 "Intervención de Alejandro Linares, Magistrado de la Corte Constitucional, visión jurídica del sector minero". Minuto 13:52 a 14:36. Asociación Colombiana de Minería. (07 de junio de 2017). Congreso ACM - Visión de la Corte Constitucional [Archivo de Video]. YouTube. Recuperado de https://www.youtube.com/watch?reload=9\&v=HNsxVCKk_zs

41 Al respecto ver Rubiano (2009): “En ciencia política y en sociología de la decisión judicial existen corrientes dedicadas a estudiar el carácter político de las cortes y de las decisiones de sus integrantes (decision-making behavior). Según esas visiones, las instituciones judiciales son el resultado del comportamiento estratégico de sus integrantes: las cortes serían, en esencia, una especie de arena de batalla en la que las preferencias políticas de sus integrantes definen sus sentencias (Sunstein et ál. 2006)" (pp. 94-95).

42 "En este orden de ideas, es claro que la sentencia T-445 de 2016 tuvo en cuenta y le dio el alcance a la subregla contenida en la sentencia C-123 de 2014 al precisar que la garantía de la participación activa y eficaz de las entidades territoriales en el proceso de autorización de minería se materializaría en que las autoridades competentes del nivel nacional deberán acordar con las autoridades territoriales concernidas las medidas necesarias para la protección del ambiente sano, y en especial, de sus cuencas hídricas, el desarrollo económico, social, cultural de sus comunidades. Sin embargo, ante la negativa de estas o la imposibilidad de lograr dicha armonización, los entes territoriales podrán 
al interior del tribunal constitucional ${ }^{43}$, modificando el balance constitucional de la votación 5-4 del Auto 053 de 2017 emitido por la sala plena. En ese orden de ideas, causa perplejidad que ni siquiera un auto de anulación sea la última palabra, y al parecer carezca de cosa juzgada material. Todo porque los nuevos magistrados cuentan con una posición distinta y la imponen en contra de lo resuelto por la corporación en casos precedentes, en abierto detrimento del stare decisis.

Como si el grave retroceso en materia del contenido del derecho fundamental de participación ciudadana no bastara, otros jueces aplicaron retroactivamente las nuevas subreglas de la Sentencia SU-095 de 2018. Ello ocurrió con una decisión del Consejo de Estado mediante la cual se resolvió conflicto de competencias administrativas entre el Ministerio de Hacienda y Crédito Público, y el municipio de Gachantivá (Boyacá), relativa a cuál autoridad debía sufragar los gastos de la consulta popular ambiental ${ }^{44}$.

Otra aplicación de este activismo regresivo sucedió cuando la Sección Primera del Consejo de Estado suspendió la consulta popular minera del municipio de San Bernardo (Cundinamarca), a partir del comunicado de prensa de la sentencia SU095 de $2018^{45}$. En contra del debido proceso, seguridad jurídica, confianza legítima, e igualdad, la aplicación retroactiva del cambio de precedente judicial también ocurrió en la Sentencia T-342 de $2019^{46}$, el Auto 281 de 2019, y la C-053 de 20197. Pero lo más discutible es que algunos actores del sector minero energético demandaron la nulidad de los acuerdos que implementaban resultados de consultas populares realizadas antes de la publicación de la SU-095 de 2018, tal como ocurrió con el acuerdo de Tauramena (Casanare) y, sin más, los jueces administrativos aplicaron retroactivamente la nueva posición de la Corte Constitucional ${ }^{48}$ accediendo a tales pretensiones, a pesar de que las consultas populares contaban con la permisión de la subregla de la Sentencia T-445 de 2016 y el Auto 053 de 2017. Como reacción

en ejercicio de sus competencias, garantizar la protección de su medio ambiente y regular los usos de su suelo incluso llegado el caso de prohibir dicha explotación" (Auto 053 de 2017).

43 Vid. https://lasillavacia.com/la-corte-constitucional-recarga-los-empresarios-y-duque-68393; https://lasillavacia. com/opinion/el-legado-de-santos-una-corte-conservadora-68394

44 Sentencia de la Sala de Consulta y Servicio Civil del Consejo de Estado del 27 noviembre 2018, radicado 11001-0306-000-2018-00152-00(C) [CP Álvaro Namén Vargas].

45 Auto del 19 de octubre de 2019, radicado 11001031500020180385400 [CP Roberto Augusto Serrato Valdés].

46 Sentencia que resolvió la acción de tutela interpuesta por concejales de Urrao (Antioquia) en contra de una sentencia del Tribunal Administrativo de Antioquia, mediante la cual se declaró sin validez el acuerdo municipal que prohibió actividades mineras de metálicos, asimismo gran y mediana minería de los demás minerales.

47 La Corte Constitucional declaró inexequible el artículo 33 de la Ley 136 de 1994, norma que establecía la obligación de realizar consultas populares, en los eventos de cambios significativos del uso del suelo.

48 Vid. https://www.ramajudicial.gov.co/documents/2196916/25926001/85001333300120160016801+Fallo+Nul idad+02.PDF 
a ello, algunos municipios decidieron desacatar el fallo de la Corte ${ }^{49}$ y surgieron voces de rechazo por parte del Movimiento Nacional Ambiental ${ }^{50}$.

Debido a las trabas impuestas a las consultas populares ambientales, otros municipios prohibieron las actividades de minería e hidrocarburos directamente mediante la expedición de acuerdos municipales sin la realización de consultas ${ }^{51}$. La estrategia fue implementada en 16 municipios de Antioquia (Amagá, Andes, Betania, Betulia, Caicedo, Concordia, Fredonia, Jardín, Jericó, Pueblorrico, Salgar, Titiribí, Támesis, Tarso, Urrao, y Venecia), uno de Boyacá (Tibaná) y uno de Quindío (Salento). Sin embargo, es probable que corran la misma suerte de Tauramena y, en contravía al cambio social y al empoderamiento ciudadano, se les aplique retroactivamente la tesis regresiva de la Sentencia SU-095 de 2018, propia de un gobierno de los jueces en contra del gobierno del pueblo.

Para finalizar, en una sociedad democrática los jueces constitucionales no deberían tener la última palabra en algunos asuntos. Lo conveniente es que estos se discutan y decidan en sus clásicos escenarios de deliberación pública, tales como el poder legislativo o ejecutivo y no en el foro de la judicatura. El riesgo es latente cuando posiciones regresivas llegan a la Corte, alteran el stare decisis y cambian el precedente de forma ilegítima, atentando contra la cosa juzgada, la seguridad jurídica, la buena fe y la confianza legítima.

\section{Conclusiones}

En Colombia los conflictos socioambientales se han desarrollado dentro del fenómeno de la expansión judicial (Feoli, 2015), en dos frentes distintos. Primero, con la judicialización de la política, los actores en pugna acuden a la judicatura, y no a otros escenarios de deliberación de asuntos públicos. La judicialización está concretada en el uso frecuente de mecanismos jurídicos, como el control previo de constitucionalidad de consultas populares, la acción de tutela contra providencias judiciales y la solicitud de nulidad de sentencias de la Corte Constitucional. La expedición de sentencias como la T-445 de 2016, Auto 053 de 2017, SU-095 de 2018, y Auto 281 de 2019 así lo evidencian. Segundo, algunas de las decisiones judiciales que resuelven conflictos socioambientales son manifestaciones del activismo judicial, al cumplir uno o algunos de los indicadores de Feoli (2015), tal como ocurrió en la Sentencia SU-095 de 2018. En ella concurren los indicadores

Vid. https://www.portafolio.co/economia/municipios-mineros-no-acatan-fallo-de-corte-constitucional-534984

Vid. https://co.boell.org/sites/default/files/cartilla_movimiento_nacional_ambiental.pdf

51 Vid. https://pacifista.tv/notas/el-arma-juridica-que-antioquia-desempolvo-para-frenar-proyectosextractivos/; https://sostenibilidad.semana.com/impacto/articulo/acuerdos-municipales-otra-alternativa-parafrenar-la-mineria-en-los-municipios/41890 
de diálogo interorgánico, interpretativo, fiscal, control de actos de otros poderes públicos, y el indicador de una decisión ultra y extra petita. Pero es regresiva porque cambió de forma ilegítima el precedente horizontal sobre la competencia de los municipios para prohibir actividades extractivas en sus territorios, al no cumplir con la carga de transparencia y argumentación. Si otro operador jurisdiccional hubiera realizado tal variación del precedente entonces se estaría en presencia de una causal de procedibilidad de acción de tutela contra providencia judicial. No obstante, como el cambio lo hizo la Corte Constitucional, de cierta manera su rol de autoridad le permite tener la última palabra y zanjar la discusión (Valdés, 2005) ${ }^{52}$, tal como se mencionó en la frase de Jackson: "No tenemos la última palabra porque seamos infalibles, sino que somos infalibles porque tenemos la última palabra"53.

Además, conforme lo expuesto se explicó por qué el cambio jurisprudencial de la SU-095 de 2018 obedeció a los cambios de mayorías de los magistrados de la Corte Constitucional. Ese viraje jurisprudencial fue ilegítimo al incumplir con la carga de la argumentación, configurando una de las causales de anulación de sentencias de la Corte Constitucional. Razón por la cual muchos actore ${ }^{54}$ acudieron a este mecanismo de control intraorgánico. Sin embargo, mediante el Auto 281 de 2019 se resolvieron las solicitudes de nulidad presentadas, dejando en firme la Sentencia SU-095 de 2018.

Si bien, por regla general los jueces constitucionales son vistos como un poder contra mayoritario y como defensores de los derechos fundamentales, también existen aquellos que están alineados con el estado de cosas imperante, al servicio de los poderes dominantes, y en contra del cambio social, a partir de decisiones activistas regresivas como la analizada.

Por tanto, la judicialización de la política supone retos para el modelo democrático, por su carácter instrumental en doble vía. Primera, refuerza la noción de democracia sustancial, en la cual ni a la mayoría más considerable le es permitido decidir en contra de lo acordado en la Constitución Política. A la postre, aunque el objeto de decisión de los tribunales constitucionales recae en tópicos políticos, los puntos en pugna se resuelven a través de instrumentos jurídicos. En especial,

52 "La Constitución, como cualquier texto que pretenda guiar la conducta de los seres humanos, dice lo que aquellos que están autorizados para interpretarla, dicen que dice. No existe mucha dificultad por la vía de la interpretación para hacer que un texto diga lo que el intérprete, al que se reconoce como el intérprete auténtico, quiere que diga; ni tampoco para que, a través de "la interpretación" de aquellos que tienen el poder, los textos sagrados y los textos fundamentales digan cosas totalmente distintas en diferentes épocas” (Valdés, 2005, p. 244).

53 Caso Brown v. Allen, de 1953 (344 U. S. 443, 540). Recuperado de https://supreme.justia.com/cases/federal/ us/344/443/

54 Municipio de Cumaral (Meta), Centro de Estudios de Derecho Justicia y Sociedad (Dejusticia), Clínica Jurídica de Medio Ambiente y Salud Pública de la Universidad de los Andes (MASP), Semillero en Estudios sobre Minería de la Facultad de Derecho y Ciencias Políticas de la Universidad de Antioquia, miembros de la comunidad académica de varios países del mundo, ciudadanos e integrantes de la Red Universitaria por la Paz (Redunipaz), y el Grupo de Litigio de Interés Público (GLIP) de la Universidad del Norte. 
con la fuerza vinculante de la Constitución como norma jurídica fundamental (García de Enterría, 1991). Segunda, con la judicialización de la política ocurre un debilitamiento de la democracia, cuando las grandes decisiones del Estado solo son tomadas por nueve magistrados, quienes promulgan su visión de mundo ${ }^{55}, \mathrm{y}$ de los intereses de quienes los apoyaron para su elección (Montoya, 2013), y no por la real vigencia de la Constitución. Tal situación exige con urgencia que desde la academia se propongan eficientes mecanismos de control internos y externos del poder judicial de las altas cortes (Bravo Restrepo, 2000; Loewenstein, 1983; Pérez Restrepo, 2000). Pero sobre todo se precisa del control social, del control de los medios de comunicación, y en general del control ejercido por los distintos sectores de opinión.

En otras palabras, se requiere reflexionar y postular soluciones desde el lente de distintas áreas del saber y no solo pensando que el discurso jurídico es el prevalente. Al contrario, por lo general este se comporta como un instrumento de legitimación formal de la opresión, la injusticia, y dominación de los actores vulnerables.

El retroceso de la Sentencia SU-095 de 2018 debe motivar a la judicialización de la política "desde abajo", en la que la sociedad civil adquiere mayor conciencia sobre sus derechos, y emprenden estrategias prácticas de movilización para presionar por sus reivindicaciones (Sieder et al., 2011).

Por último, en aras de decantar la manifestación o no del activismo judicial, este se debe analizar en concreto en sede de providencias específicas, las cuales pueden ser progresistas o regresivas, considerando como baremo los precedentes judiciales aplicables (stare decisis), y a partir de los indicadores de Feoli (2015).

\section{Referencias bibliográficas}

Aguiló Regla, J. (2003). De nuevo sobre "independencia e imparcialidad de los jueces y argumentación jurídica". En G. Burgos Silva (ed.), Independencia judicial en América Latina. ¿De quién? ¿Para qué? ¿Cómo? (pp. 65-82), Bogotá: ILSA.

Alexy, R. (2009). Los derechos fundamentales en el Estado constitucional democrático. En M. Carbonell (ed.), Neoconstitucionalismo(s) (pp. 31-47). Madrid: Trotta Editorial.

55 "Si la política del Gobierno sobre las cuestiones vitales que afectan a todo el pueblo va a ser fijada irrevocablemente por decisiones de la Suprema Corte, en el instante en que así se hace en litigios ordinarios entre partes en acciones personales, el pueblo habrá dejado de ser su propio amo, al renunciar prácticamente a su Gobierno para dejarlo en manos de ese eminente tribunal" (Lincoln, 1861). 
Asociación Colombiana de Minería. (07 de junio de 2017). Congreso ACM - Visión de la Corte Constitucional [Archivo de Video]. YouTube. Recuperado de https://www. youtube.com/watch?reload=9\&v=HNsxVCKk_zs

Bernal, C. (2005). El derecho de los derechos. Bogotá: Universidad Externado de Colombia.

Bravo Restrepo, L. A. (2000). Legitimidad del control constitucional y los controles a la Corte Constitucional. Revista Estudios de Derecho de la Facultad de Derecho y Ciencias Políticas de la Universidad de Antioquia, 59(133-4), 73-95. Recuperado dehttps://revistas.udea.edu.co/index.php/red/article/view/332252/20788161

Cárdenas, M. y Reina, M. (2008). La minería en Colombia: Impacto socioeconómico y fiscal. Bogotá: Cuadernos de Fedesarrollo.

Colombia. Asamblea Nacional Constituyente. (1991). Constitución Política. Gaceta Constitucional n. 114 . Bogotá. Recuperado de http://www.secretariasenado. gov.co/senado/basedoc/constitucion_politica_1991.html

Colombia, Congreso de la República. (22 de diciembre de 1993). Ley 99 de 1993. Por la cual se crea el Ministerio del Medio Ambiente, se reordena el Sector Público encargado de la gestión y conservación del medio ambiente y los recursos naturales renovables, se organiza el Sistema Nacional Ambiental, SINA y se dictan otras disposiciones. Diario Oficial n.o 41.146. Recuperado de http://www.secretariasenado.gov.co/senado/basedoc/ley_0099_1993.html

Colombia, Congreso de la República. (31 de mayo de 1994). Ley 134 de 1994. Por la cual se dictan normas sobre mecanismos de participación ciudadana. Diario Oficial n. ${ }^{\circ}$ 41.373. Recuperado de http://www.secretariasenado.gov.co/senado/ basedoc/ley_0134_1994.html

Colombia, Congreso de la República. (2 de junio de 1994). Ley 136 de 1994. Por la cual se dictan normas tendientes a modernizar la organización y el funcionamiento de los municipios. Diario Oficial n. o 41.377. Recuperado de http://www.secretariasenado.gov.co/senado/basedoc/ley_0136_1994.html

Colombia, Congreso de la República. (7 de marzo de 1996). Ley 270 de 1996. Ley Estatutaria de la Administración de Justicia. Diario Oficial n. - 42.745. Recuperado de http://www.secretariasenado.gov.co/senado/basedoc/ley_0270_1996.html

Colombia, Congreso de la República. (24 de julio de 1997). Ley 388 de 1997. Por la cual se modifica la Ley 9a de 1989 , y la Ley 3a de 1991 y se dictan otras disposiciones.

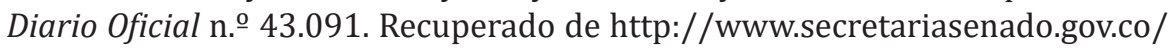
senado/basedoc/ley_0388_1997.html

Colombia, Congreso de la República. (15 de agosto de 2001). Ley 685 de 2001. Por la cual se expide el Código de Minas y se dictan otras disposiciones.

Diario Oficial n.o 44.545. Recuperado de https://www.minambiente.gov.co/images/ normativa/leyes/2001/ley_0685_2001.pdf

Colombia, Congreso de la República. (28 de junio de 2011). Ley 1454 de 2011. Por la cual se dictan normas orgánicas sobre ordenamiento territorial y se modifican 
otras disposiciones. Diario Oficial n.o 48.115. Recuperado de http://www.secretariasenado.gov.co/senado/basedoc/ley_1454_2011.html

Colombia, Congreso de la República. (17 de diciembre de 2013). Ley 1695 de 2013. Por medio de la cual se desarrolla el artículo 334 de la Constitución Política y se dictan otras disposiciones. Diario Oficial n.o 49.007. Recuperado de http://www. secretariasenado.gov.co/senado/basedoc/ley_1695_2013.html

Colombia, Congreso de la República. (6 de julio de 2015). Ley 1757 de 2015. Por la cual se dictan disposiciones en materia de promoción y protección del derecho a la participación democrática. Diario Oficial n. 49.565. Recuperado de http:// www.secretariasenado.gov.co/senado/basedoc/ley_1757_2015.html

Colombia, Consejo de Estado, Sección Primera. (28 de marzo de 2014). Sentencia del 28 de marzo de 2014, expediente número AP-25000-23-27-000-2001-90479-01. [CP Marco Antonio Velilla Moreno]. Recuperado de http://www.mincit.gov.co/normatividad/jurisprudencia/sentencia-ap-25000-23-27-000-2001-90479-01.aspx

Colombia, Consejo de Estado, Sala de lo Contencioso Administrativo, Sección Segunda. (12 de mayo de 2014). Sentencia del 12 mayo 2014. Número radicado 11001031500020140078800 .

Colombia, Consejo de Estado, Sala de lo Contencioso Administrativo, Sección Cuarta. (7 de diciembre de 2016). Sentencia del 07 diciembre 2016. Número radicado 11001031500020160239600.

Colombia, Consejo de Estado, Sala de lo Contencioso Administrativo, Sección Quinta (15 de diciembre de 2016). Sentencia del 15 de diciembre de 2016. Número radicado 11001031500020160341500.

Colombia, Consejo de Estado, Sala de lo Contencioso Administrativo, Sección Primera. (23 de febrero de 2017). Sentencia del 23 de febrero de 2017. Número radicado 11001031500020160300200.

Colombia, Consejo de Estado, Sala de lo Contencioso Administrativo, Sección Primera. (19 de diciembre 2018). Sentencia del 19 de diciembre 2018. Número radicado 11001031500020180385400.

Colombia. Corte Constitucional. (13 de noviembre de 2001). Sentencia T-1182/01. [MP Alfredo Beltrán Sierra].

Colombia. Corte Constitucional. (5 de marzo de 2014). Sentencia C-123/14 [MP Alberto Rojas Ríos].

Colombia. Corte Constitucional. (19 de agosto de 2016). Sentencia T-445/16. [MP Jorge Iván Palacio Palacio].

Colombia. Corte Constitucional. (08 de febrero de 2016). Sentencia C-035 de 2016. [MP Gloria Stella Ortiz Delgado].

Colombia. Corte Constitucional. (15 de febrero de 2017). Auto 053 de 2017. [MP Jorge Iván Palacio Palacio]. 
Colombia. Corte Constitucional. (11 de octubre de 2018). Sentencia SU-095 de 2018. [MP Cristina Pardo].

Colombia. Corte Constitucional. (29 de mayo de 2019). Auto 281 de 2019. [MP Cristina Pardo].

Colombia. Corte Constitucional. (13 de febrero de 2019). Sentencia C-053/19. [MP Cristina Pardo Schlesinger].

Colombia. Corte Constitucional. (30 de julio de 2019). Sentencia T-342/19. [MP Luis Guillermo Guerrero Pérez].

Colombia. Corte Suprema de Justicia. (05 de abril de 2018). Corte Suprema ordena protección inmediata de la Amazonía Colombiana. Recuperado de http://www. cortesuprema.gov.co/corte/index.php/2018/04/05/corte-suprema-ordenaproteccion-inmediata-de-la-amazonia-colombiana/

Colombia, Presidente de la República. (19 de noviembre de 1991). Decreto 2591 de 1991. Por el cual se reglamenta la acción de tutela consagrada en el artículo 86 de la Constitución Política. Diario Oficial n. 40.165. Recuperado de http://www. secretariasenado.gov.co/senado/basedoc/decreto_2591_1991.html

Colombia, Presidente de la República. (23 de diciembre de 2014). Decreto 2691 de 2014. Por el cual se reglamenta el artículo 37 de la Ley 685 de 2001 y se definen los mecanismos para acordar con las autoridades territoriales las medidas necesarias para la protección del ambiente sano, y en especial, de sus cuencas hídricas, el desarrollo económico, social, cultural de sus comunidades y la salubridad de la población, en desarrollo del proceso de autorización de actividades de exploración y explotación minera. Recuperado de https://www.funcionpublica. gov.co/eva/gestornormativo/norma.php?i=60227

Dueñas, O. (2015). Lecciones de hermenéutica jurídica. Bogotá: Editorial Universidad del Rosario.

Feoli, M. (2015). El nuevo protagonismo de los jueces: una propuesta para el análisis del activismo judicial. Revista de derecho (Coquimbo), 22(2), 173-198. Recuperado de https://scielo.conicyt.cl/scielo.php?pid=S071897532015000200006\&script=sci_arttext\&tlng=n

Fierro, J. (2012). Políticas mineras en Colombia. Bogotá: ILSA. Recuperado de http:// www.ilsa.org.co/biblioteca/Textos_de_aqui_y_ahora/completo.pdf

García de Enterría, E. (1991). La constitución como norma y el tribunal constitucional. Madrid: Editorial Civitas S.A.

García Jaramillo. L (2016). Activismo judicial y dogmática de los márgenes de acción: Una discusión en clave neoconstitucional. México: Instituto de Estudios Constitucionales.

Gaviria Díaz, C. (2018). Nueva actitud frente a la interpretación del Derecho. En Carlos Gaviria Díaz. 9 conferencias 9 (pp.63-79). Medellín: Facultad de Derecho y Ciencias Políticas de la Universidad de Antioquia y Señal Editora. 
Guastini, R. (2010). Teoría e ideología de la interpretación constitucional. Madrid: Mínima Trotta e Instituto de Investigaciones Jurídicas UNAM.

Guzmán, L. F. (2017). El activismo judicial y su impacto en la construcción de políticas públicas ambientales. Análisis de caso en el derecho jurisprudencial de la Corte Constitucional y el Consejo de Estado. Bogotá, Universidad Externado de Colombia.

Hernández Sampieri, R., Fernández, C, y Baptista, M. (2010). Metodología de la investigación. México: The McGraw-Hill C.

Kennedy, D. (2010). Izquierda y derecho. Ensayos de teoría jurídica crítica. Buenos Aires: Siglo XXI.

Juzgado Primero Administrativo de Yopal. Sentencia del 25 de octubre de 2018. Número radicado 85001233300120160016800 .

López Medina, D. E. (2018). El derecho de los jueces. Obligatoriedad del precedente constitucional, análisis de sentencias y líneas jurisprudenciales y teoría del derecho judicial. Bogotá: Universidad de los Andes y Legis.

López Sterup, H. (2018). Separación de poderes, políticas públicas y activismo judicial: Una discusión a partir de jurisprudencia de la Corte Constitucional colombiana sobre una política pública. Doxa. Cuadernos de Filosofía del Derecho, (41), 171192. DOI: 10.14198/DOXA2018.41.09

Loewenstein, K. (1983). Teoría de la constitución. Barcelona: Editorial Ariel.

Montoya, A. M. (2013). "Si no vas al Senado, no te eligen magistrado”. Instituciones informales y criterios de selección de los magistrados de la Corte Constitucional colombiana en el Senado (1992-2009). Colombia Internacional, (79), 155-190. DOI: https://doi.org/10.7440/colombiaint79.2013.06

Negrete, R. (2017). Competencia municipal para la prohibición de actividades mineras y de hidrocarburos. Ideas Verdes, (2), 1-24. Recuperado de https://co.boell.org/ sites/default/files/20180205_ideasverdes_no2_completo_web.pdf

Osuna, N. (2015). Las sentencias estructurales. Tres ejemplos de Colombia. En V. Bazán (ed.), Justicia constitucional y derechos fundamentales. La protección de los derechos sociales. Las sentencias estructurales (pp. 91-117). Bogotá: Fundación Konrad Adenauer.

Pardo, L. A. (2013). La conflictividad por el territorio, el control de los RNNR y la renta minera. El choque de las locomotoras mineras en Colombia. En Contraloría General de la República (ed.)., Minería en Colombia. Institucionalidad y territorio, paradojas y conflictos (pp. 143-191). Bogotá: Contraloría General de la República.

Pardo, L. A. (2018). Extractivismo, derechos y tributación: Cooptación del Estado colombiano. Un caso de estudio. Ideas Verdes, (11), 1-32. Recuperado de https:// co.boell.org/sites/default/files/20181003_ideas_verdes_11_web.pdf

Pásara, L. (2007). Estado de derecho y sistema de justicia en América Latina. Revista Oficial del Poder Judicial, Corte Suprema de Justicia de la República de Perú, 1(1), 
309-323. Recuperado de https://revistas.pj.gob.pe/revista/index.php/ropj/ article/view/104

Pérez Restrepo, B. (2000). Límites y controles a la justicia constitucional. Letras Jurídicas, 5(2), 197-213.

Red por la Justicia Ambiental en Colombia. (10 de agosto de 2018). Tribunal de Boyacá declara páramo de Pisba como sujeto de derecho y reconoce la participación campesina en la delimitación. Recuperado de https://redjusticiaambientalcolombia. files.wordpress.com/2018/08/fallo-pisba.pdf

Registraduría Nacional del Estado Civil. (2018). Habitantes de Cumaral (Meta) dijeron no a los hidrocarburos. Recuperado de https://www.registraduria.gov.co/ Habitantes-de-Cumaral-Meta-dijeron.html

Rubiano, S. (2009). La Corte Constitucional: Entre la independencia judicial y la captura política. En M. García y J. Revelo (coeditores), Mayorías sin democracia. Desequilibrio de poderes y Estado de derecho en Colombia, 2002-2009 (pp. 84-145). Bogotá: Centro de Estudios de Derecho, Justicia y Sociedad, Dejusticia.

Rudas, G. (2014). Revisitando el debate sobre renta minera y government take: El carbón a gran escala en Colombia. En Contraloría General de la República (ed.), Minería en Colombia. Daños ecológicos y socio-económicos y consideraciones sobre un modelo minero alternativo (pp. 309-378). Bogotá: Contraloría General de la República.

Rudas, G. y Espitia, J. (2013). Participación del Estado y la sociedad en la renta minera. En Contraloría General de la República (ed.), Minería en Colombia. Fundamentos para superar el modelo extractivista (pp. 125-172). Bogotá: Contraloría General de la República.

Saffon, M. P. y García-Villegas, M. (2011). Derechos sociales y activismo judicial. La dimensión fáctica del activismo judicial en derechos sociales en Colombia. Revista Estudios Socio-Jurídicos, 13(1), 75-107. Recuperado de https://revistas.urosario. edu.co/index.php/sociojuridicos/article/view/1511/1404

Santaella, H. (2016). Un territorio y tres modelos de gestión: Análisis de la necesidad de armonizar y constitucionalizar las competencias urbanísticas, ambientales y mineras sobre el territorio. J. C. Henao y S. Díaz (eds.), Minería y Desarrollo (Tomo 5. Historia y gobierno del territorio minero) (pp. 165-225). Bogotá: Universidad Externado de Colombia.

Sieder, R., Schjolden, L. y Angell, A. (Coordinadores). (2011). La judicialización de la política en América Latina. México: Centro de Investigaciones y Estudios Superiores en Antropología Social (CIESAS), y Universidad Externado de Colombia.

Timm Hidalgo, A. K. (2017). Activismo judicial dialógico en América Latina. La lucha por los derechos (Tesis doctoral). Instituto de Derechos Humanos "Bartolomé de Las Casas", Universidad Carlos III de Madrid, España. Recuperado de https://earchivo.uc3m.es/bitstream/handle/10016/24578/Tesis_ana_timm_2017.pdf 
Valdés, C. (2005). Marbury vs. Madison. Un ensayo sobre el origen del poder de los jueces en Estados Unidos. Revista Académica de la Facultad de Derecho de la Universidad La Salle, 5, 219-256. Recuperado de https://repositorio.lasalle.mx/bitstream/ handle/lasalle/327/N\%c3\%bam.5_P.219-256.pdf?sequence=2\&isAllowed=y

Vargas, F. (2014). Propiedad sobre el subsuelo y los recursos mineros: Aportes comparativos para analizar el caso colombiano. Contraloría General de la República (ed.), Minería en Colombia. Daños ecológicos y socio-económicos y consideraciones sobre un modelo minero alternativo (pp. 271-307). Bogotá: Contraloría General de la República.

Villar, L., Castro, F., Forero, D., Ramírez, J. M. y Reina, M. (2014) Evaluación de la contribución económica del sector de hidrocarburos colombiano frente a diversos escenarios de producción. Bogotá: Fedesarrollo. 